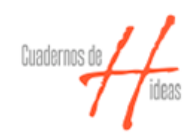

Cuadernos de $\mathrm{H}$ ideas

ISSN: 2313-9048

cuadernosdehideas@perio.unlp.edu.ar

Universidad Nacional de La Plata

Argentina

\title{
Familia y trabajo rural en la Argentina contemporánea: una mirada desde Concepción del Uruguay
}

\author{
Bergara, Rogelio \\ Familia y trabajo rural en la Argentina contemporánea: una mirada desde Concepción del Uruguay \\ Cuadernos de $\mathrm{H}$ ideas, vol. 12, núm. 12, 2018 \\ Universidad Nacional de La Plata, Argentina \\ DOI: https://doi.org/10.24215/23139048e012
}

Esta obra está bajo una Licencia Creative Commons Atribución-NoComercial-SinDerivar 4.0 Internacional. 
Artículos

\section{Familia y trabajo rural en la Argentina contemporánea: una mirada desde Concepción del Uruguay}

Family and rural work in contemporary Argentina: a look from Concepción del Uruguay

Rogelio Bergara brbergara79@gmail.com

Universidad Nacional de Luján, Argentina

Cuadernos de H ideas, vol. 12, núm. 12, 2018

Universidad Nacional de La Plata, Argentina

Recepción: 01 Noviembre 2018 Aprobación: 03 Diciembre 2018

\section{DOI: https://}

doi.org/10.24215/23139048e012

\section{BY-NC-ND}

Resumen: El presente trabajo tiene como objetivo principal reconstruir parte de la cotidianeidad laboral y social del denominado "mundo chacarero" a partir del estudio de caso del matrimonio Bergara-Marín y sus hijos e hijas en el tiempo que desarrollaron actividades productivas en carácter de "colonos-arrendatarios" en la estancia Centella, situada en el Departamento de Uruguay; en la provincia de Entre Ríos. El marco temporal se extiende desde principios de la década de 1930 hasta el año 1968. El trabajo de alambrador, las cosechas, la producción familiar, la crianza de animales domésticos, la mantención del hogar y el proceso de urbanización familiar son el cuerpo fundamental del trabajo en cuanto a la reafirmación de identidades y lazos familiares que permiten la reconstrucción de la cotidianeidad del denominado "mundo chacarero".

Palabras clave: Familia, trabajo rural, cotidianeidad.

Abstract: The main objective of this work is to reconstruct part of the labor and social daily life of the so-called "chacarero world" from the case study of the BergaraMarín marriage and their sons and daughters during the time they developed productive activities as "settlers- tenants "at the Centella ranch, located in the Department of Uruguay; in the province of Entre Ríos. The time frame extends from the early 1930s to the year 1968. Wiring work, harvests, family production, raising domestic animals, maintaining the home and the process of family development are the fundamental body of work in terms of the reaffirmation of identities and family ties that allow the reconstruction of the daily life of the so-called "chacarero world"

Keywords: Family, rural work, daily life.

\section{Introducción}

El presente trabajo es parte de una investigación más amplia en la cual se planteó analizar, comprender y reconstruir fragmentos de la cotidianeidad laboral, social y productiva del denominado "mundo chacarero" a partir de un estudio de caso: el del matrimonio Jacinto Bergara-Lucila Marín y sus hijos e hijas en el tiempo que desarrollaron actividades productivas en carácter de "colonos-arrendatarios" en la Estancia Centella, situada al sur del Departamento de Uruguay, en la provincia de Entre Ríos. El marco temporal se corresponde desde principios de la década de 1930 hasta el año en que abandonan definitivamente la estancia, en 1968.

Más allá de analizar el protagonismo del colectivo familiar en la producción, su cotidianeidad y la reproducción social y económica; este 
trabajo permite analizar a su vez siguiendo a Javier Balsa, la rapidez con la que se desvanece el mundo chacarero; es decir el poco arraigo de la tradición chacarera y las razones por las que esta familia de agricultores y las formas de vida rural no perduran más allá de una generación.

La metodología se basó principalmente en entrevistas en profundidad realizadas a seis de los doce hijos del matrimonio, nacidos entre 1925 y 1946; desde las cuales se reconstruye la cotidianeidad. Cuatro de ellos, residen desde hace décadas en la ciudad bonaerense de Campana. Uno de ellos lo hace en Gualeguaychú, quedando la restante, en Concepción del Uruguay. El resto de los seis hijos del matrimonio, han fallecido en diversos momentos y circunstancias. De estos últimos se tomó en algunos casos el testimonio de sus esposas, así como el de sus hijos e hijas mayores, es decir de los nietos y nietas de Jacinto y Lucila que llegaron a compartir parte de su infancia y juventud en Centella. Por lo tanto, lo que permitió la reconstrucción de la cotidianeidad fueron dichas entrevistas; entendiendo lo cotidiano "como aquello que se caracteriza por la reiteración, por su naturaleza habitual, siguiendo la cadencia del ritmo temporal que marcan las horas, los dias, las semanas y las estaciones del año" (1).

Es importante destacar además, que trabajamos sobre percepciones; es decir con los recuerdos de una sociabilidad que se quiere rescatar y en la que esos años de "colonos-arrendatarios" arrojan la construcción de un mundo feliz. Este mundo feliz es matizado por el hecho de que los recuerdos de esos años, más allá de los sacrificios laborales y domésticos; para los protagonistas son al día de hoy positivos, y pueden sintetizarse en una palabra: añoranza.

Para respaldar algunos datos surgidos de las entrevistas, se consultaron diversas fuentes parroquiales en Concepción del Uruguay y Gualeguaychú; así como en el Registro del Estado Civil y Capacidades de las Personas, sito en Paraná. De la información obtenida en dichas actas se reafirmó la trayectoria del matrimonio por diversas estancias del departamento de Uruguay hasta que finalmente se establecieron en Centella, a principios de la década del 30. En esta última, se asentaron en tres lugares diferentes, denominados colonias. La primera de ellas fue la llamada "Colonia San José". Alrededor de 1937 fueron trasladados a la "Colonia Centella" y finalmente hacia 1942 a la "Colonia El Salto" o "Salto de Piedra", siempre en la misma estancia. Cabe aclarar que la descripción y reconstrucción de la cotidianeidad del presente trabajo, corresponde sobre todo al tiempo que vivieron en la llamada "Colonia El Salto".

Por último, debemos decir que la temática aquí desarrollada pretende ser sólo un punto de partida para reafirmar no sólo identidades y los lazos familiares en relación con la reconstrucción de parte de la cotidianeidad del denominado "mundo chacarero" a partir de percepciones; sino también para analizar la reproducción social familiar; es decir la relación existente entre trabajo doméstico y excedente, entendiendo al primero como el llevado a cabo principalmente por las mujeres de la casa y los hijos menores y al segundo; por el tipo de producción mercantilizada. De esta 
investigación esperamos se desprendan nuevos datos y aproximaciones, así como investigaciones sobre la relación familia-trabajo rural en la Argentina contemporánea.

\section{1- Consideraciones generales}

\section{1- Familia y trabajo rural}

En primera instancia debemos aclarar qué significa para muchos autores la colonización, ya que el mismo difiere sustancialmente de nuestro concepto de "colonos-arrendatarios". Existe una definición comúnmente aceptada que "colonización significaba subdividir una determinada superficie de tierra para venderla a plazos a agricultores, por lo general extranjeros aunque también argentinos, quienes se comprometian a cultivar bajo ciertas condiciones durante algunos años"; (2) o a la acción y efecto de colonizar; esto es, "establecer una colonia o bien fijar en un terreno la morada de quienes la cultivarán".(3) Es decir, en un sentido amplio, el término refiere al poblamiento, "al asentamiento de una población (colonos) en una zona deshabitada y con una actividad productiva inexistente o no acorde con sus potencialidades".(4) En nuestro caso la colonización no se ajusta a este tipo de definiciones, así como tampoco el ser arrendatario. Del arrendamiento diremos que en nuestro caso son formas de producción semejantes a la mediería. Mantuvimos a lo largo del trabajo el concepto de "colonos-arrendatarios" ya que surgió en todas las entrevistas realizadas como forma identitaria del grupo familiar; adoptada como autodenominación.

Para nuestro análisis, más allá de los autores ya mencionados, partimos de una serie de trabajos que nos permiten observar cómo el tipo de "colonias de arrendatarios" y la forma de trabajo aquí estudiada, no se amoldan en general a las configuraciones desarrolladas desde diversas miradas y perspectivas; entre los que podemos citar a Carl Taylor,(5) James Scobie,(6) Miguel Gallo (7) y Javier Balsa (8) entre otros. Del primero de ellos tomamos sobre todo su base metodológica (más allá de la diferencia del tamaño de la muestra), ya que a partir de entrevistas y análisis de fuentes primarias y secundarias, Taylor construye una mirada no sólo sobre la composición de las unidades productivas, su relación con el medio que habitan y las relaciones sociales que construyen, sino también; en el origen, la composición y habitad familiar del mundo rural en diversos lugares de la Argentina. La vivienda, el rol de la mujer y los hijos y la cotidianeidad ocupan asimismo un lugar destacado en su estudio.

Del texto de Scobie hemos tomado, fundamentalmente la configuración que tendió a arraigarse en la historiografía argentina sobre el tipo de unidad productiva o fuerza de trabajo disponible en las zonas rurales de nuestro país: ser colono, ser arrendatario, mediero y, peón rural o golondrina, (9) más allá de que el tipo de unidad productiva y trabajo disponible no se ajuste con nuestro caso.

Por su parte, Miguel Gallo realiza un recorrido histórico sobre la importancia de la inmigración (aunque no sólo de ella), en el proceso de 
poblamiento y explotación económica en las zonas rurales en la provincia de Santa Fe durante el último tercio del Siglo XIX.(10) Con respecto a los tipos de colonización Gallo analiza el surgimiento y desarrollo de las colonias gubernamentales, colonias oficiales, colonias privadas y las colonias particulares.(11) Si bien La pampa gringa no es un texto de reconstrucción de vida cotidiana propiamente dicha, podemos decir que es una obra fundamental para comprender a qué nos referimos cuando hablamos del proceso de colonización, los diversos elementos que surgen de ella y, de manera fundamental; el papel jugado por el Estado, los inversores privados y los inmigrantes. Esta conceptualización aportada por Ezequiel Gallo, así como por Scobie, Julio Djenderedjian y Mónica Blanco; nos mostrará una vez más que nuestro tipo de colonización y nuestro ser arrendatario, poco tiene que ver con las experiencias históricas por ellos trabajada.

Por último, y sin dudas el texto que más puntos de contacto tiene con nuestra investigación, es El desvanecimiento del mundo chacarero de Javier Balsa. En el desarrollo de los capítulos, el autor plantea una descripción general en relación al tipo de explotación característica en la provincia de Buenos Aires entre 1937 y 1988; y en forma particular de los tres partidos que estudia. Balsa distingue y caracteriza diversas formas sociales de producción tales como los arrendatarios familiares sin asalariados permanentes, los arrendatarios familiares con asalariados, los arrendatarios empresariales, los farmers y los terratenientes-capitalistas. A partir de esta caracterización, el autor advierte que "el trabajo familiar ocupa un lugar significativo en el conjunto de la mano de obra utilizada en la producción agricola hacia 1937”.(12) Desarrolla además, que en la mayoría de las unidades chacareras, "la familia constituia un equipo de producción en el que la mujer y los niños se encargaban, por lo general, de los bienes para el autoconsumo".(13) Esta producción acompaña las actividades propiamente dichas, construyendo una cotidianeidad per se, que implica necesariamente, el compromiso de los diversos actores familiares en las actividades domésticas. Una última visión de las tratadas por el autor que es preciso destacar, es la relacionada con la urbanización de los productores agropecuarios. Según él, esta urbanización llevó a la transformación del modo de vida de los agricultores y fundamentalmente, al desvanecimiento del mundo rural chacarero.

\section{2- Familia y hogar}

En relación a este punto, seleccionamos como base teórica referencial para este artículo; dos trabajos sobre la historia de la familia. Por un lado la obra clásica de Michael Anderson,(14) y por otro lado la Historia de la familia en el Río de la Plata de José Luis Moreno. La primera fue tomada principalmente en sus aspectos teóricos y metodológicos, y la segunda por la descripción de la familia como "célula constitutiva de todo ente social, como fuente esencial de la socialización de los individuos, y como motor propulsor de las iniciativas individuales de hombres y mujeres en el plano económico, social, político y cultural" (15). 
Anderson analiza tres de las cuatro aproximaciones al estudio de la familia occidental: la aproximación demográfica; a través de los sentimientos y la de la economía doméstica. En el presente trabajo se tuvieron en cuenta dos de ellas: la aproximación a través de los sentimientos y la de la economía doméstica; tomando los modelos de análisis e interpretaciones desarrollados por el autor. Asimismo, tomamos la idea de hogar desarrollada por Moreno, entendiendo al mismo como "el lugar de reunión de los miembros de un grupo familiar, del ámbito en donde se toman las decisiones de la vida cotidiana, y donde se comparten los alimentos, el lecho para reposar, las actividades domésticas o económicas, el medio en que aparecen y se expresan el afecto y las relaciones sexuales" (16).

\section{2- Actividades agropecuarias en Entre Ríos}

A mediados del siglo XIX, coincidiendo con el planteo de la obra clásica de Alejandro Rofman y Luis Alberto Romero (17) en que los territorios que conformarán la Argentina se incorporan de lleno al mercado mundial capitalista, Osvaldo Barsky y Jorge Gelman plantean que Entre Ríos "entre 1850 y 1880 continúa el proceso de crecimiento que venia experimentando por lo menos desde los años '30".(18) Se da en este proceso "la consolidación de la producción ganadera, que sigue siendo en gran parte vacuna y vinculada con el saladero, pero que también incorpora al ovino".(19) Roy Hora sin embargo, plantea que "en las décadas de 1830 y 1840, el dinamismo de su ganadería le permitió a la provincia vivir el momento más próspero de toda su trayectoria".(20) Es decir que en una primera instancia, las caracterizaciones que realizan los historiadores mencionados, no coinciden con respecto al período de mayor progreso económico de la provincia, aunque si en la actividad determinante del proceso productivo: la ganadería. En relación a este punto, Julio Djenderedjian coincide con Roy Hora en situar a la década de 1830 como la década más próspera, más allá de las dificultades en relación a "la escasez de mano de obra acentuado con el fin de la esclavitudy con el reclutamiento de buena parte de los varones para servir en los ejércitos en marcha";(21) ya que el autor menciona que fue precisamente la escasez de mano de obra uno de los factores que permitieron el desarrollo de la ganadería.

Es decir que en plena génesis de la organización económica agroexportadora, la provincia tuvo un marcado predominio de la actividad ganadera, aportando parte de su producción al mercado de exportación. Esta situación beneficiosa, tendría un marcado declive a partir de un factor clave en el desarrollo del denominado Modelo Agroexportador en nuestro país: la llegada y expansión del Ferrocarril. Entre Ríos presenta cursos de agua que hacían imposible pensar en grandes obras de infraestructura como los que hoy se emplazan; por lo que el factor geográfico que en momentos de preponderancia de la navegación permitió un crecimiento sostenido a la provincia, en los tiempos de expansión ferroviaria actuó de manera perjudicial. La velocidad con la cual se transportaba la producción hacia los puertos 
de Buenos Aires y Rosario, posibilitaron el crecimiento acelerado de otras regiones, provocando en Entre Ríos, un marcado estancamiento, ya que "el copioso entramado de lineas férreas no pudo sortear la valla que la naturaleza habia creado y apenas incorporó algunos puertos y ciudades de la zona mesopotámica".(22) Si bien la provincia no se encontraba completamente aislada; el impulso económico sobre los bienes primarios exportables y la expansión ferroviaria de fines del Siglo XIX y principios del XX; no tuvieron el impacto de otras regiones en las cuales no se presentaban cursos de agua de la magnitud del Río Paraná. Además, a esta situación desventajosa provocada de la relación negativa entre desarrollo ferroviario y cursos de agua; hay que sumar que en el plano provincial interno "la transitabilidad de la red caminera dependia de las condiciones meteorológicas"(23).

Asimismo, durante los años 30 del siglo XX, Entre Ríos no fue ajena al impacto de la Crisis del 29 y su posterior recesión, que se hizo sentir con fuerza en el comercio de exportación. El país comenzó un sostenido proceso de industrialización, con el eje puesto en aquellas ramas que podían usufructuar las materias primas disponibles. En este sentido, es necesario aclarar que para Biasizo, "la Industrialización por Sustitución de Importaciones no es aplicable para el caso entrerriano, si bien lo es para la economía argentina en su conjunto".(24) Para analizar el caso de la provincia, el autor plantea que "la Agricultura de Sustitución o Agriculturización es la más apropiada para explicar el caso de la intervención en la economia entrerriana, sobre todo en cuanto a la estrategia del Estado Provincial'.(25) A partir de la década del 30 se observan modificaciones en la economía entrerriana que tienen que ver con su estructura sectorial, como también con la distribución territorial de las actividades económicas. Se observa una característica dual de la provincia en lo que hace a su geografía. Esto es, su condición de región pampeana en el centro sur, y su condición de región no pampeana desde el centro al norte. De allí "la especialización territorial pecuaria y agrícola pampeana en la primera, y el mayor desarrollo de cultivos industriales y frutales en el centro norte" (26).

Recordemos que la Estancia Centella encuentra situada en el sur del Departamento de Uruguay, es decir en una zona con similitudes en lo productivo a partir de condiciones de clima y en menor medida de suelo, a la región pampeana. Por ende, veremos a lo largo de los apartados específicos, que la producción agraria se centraba en productos tales como el trigo, maíz, sorgo, lino y otros cultivos característicos de la Región pampeana.

Avanzada la década del 30 y entrando en los años 40, producto del impacto a largo plazo de la crisis de 1929, "los bajos precios y la reducción en la demanda de granos internacionales produjeron la falta de inversión y una disminución en el área sembrada, cuyas tierras fueron ocupadas por la ganadería".(27) Esta situación llevó a que se sucedieran una serie de conflictos, ya que "los desalojos y los reclamos de los arrendatarios para convertirse en propietarios eran incesantes". (28) Las condiciones generales en las que se encontraban los agricultores entrerrianos, la relación con los 
propietarios de la tierra y el rol del Estado, serán abordados en el siguiente apartado.

\section{3- La estancia Centella y las "colonias de arrendatarios"}

$\mathrm{Al}$ momento en que el matrimonio Bergara/Marín desarrollaba sus actividades productivas, la Estancia Centella era propiedad de la familia Blaquier-Unzué. Estos territorios fueron parte de la gran Estancia "Potrero de San Lorenzo", mantenidas como unidad productiva hasta la adquisición por parte de Saturnino E. Unzué y Mariano Unzué en 1877 conformando un condominio al que hay que sumar a Guillermo Rodger Gilmour.(29) A la muerte de los hermanos Unzué, los diversos trámites sucesorios y los matrimonios celebrados llevaron a que esa primera gran estancia se convirtiera en diversos establecimientos, entre los cuales se encontraba Centella. La familia Blaquier-Unzué continúa con la explotación de la tierra, que tendrá la particularidad de establecer una "colonia de arrendatarios". Recordemos nuevamente que no hablamos de la colonización en el sentido clásico del término, sino como autodenominación familiar.

Con respecto al por qué, en el caso particular de Centella, estableció este tipo de "colonias" podemos realizar diversas interpretaciones e inferencias, ya que en realidad de colonias sólo tenían el nombre, así como el "ser" arrendatario. Sabido es, que toda situación que atañe a la vida social y en este caso productiva está, o al menos debería estarlo, regulado por leyes y/o decretos para que su funcionamiento sea efectivo. Pero también es más que claro que el marco legal interviene para resolver o refrendar situaciones preexistentes. Si bien a nivel nacional habían sido sancionadas la ley de Arrendamientos No 11.170 en 1921 y la ley de Cooperativas Agrícolas № 11.380 en 1926; la provincia llevó adelante en principio, su propia política con la Constitución Provincial sancionada en 1933 y la ley de Transformación Agraria, sancionada en junio de 1934. En la Constitución se explicita y profundiza ese rol estatal en las de iniciativas destinadas a este tipo de proyectos de colonización, y en la ley de Transformación Agraria se esbozan una serie de preceptos organizadores de la colonización. A partir de la entrada en escena de la Constitución Provincial y la ley de Transformación, se conformaron luego de 1934 seis colonias oficiales en diversos lugares de la provincia (30).

Ahora bien, las colonias de la estancia Centella, no se asemejan a ese tipo de experiencias; sino de ofrecimientos temporales de las estancias a pobladores con escaso o nulo capital que en su gran mayoría, no estaban en condiciones de arrendar y en la cual los estancieros sólo podían usufructuar parte del producto de la cosecha. Es decir una situación más cercana a la mediería que al arrendamiento propiamente dicho. Estas "colonias de arrendatarios", según los testimonios, eran comunes en diversas estancias de la zona desde finales de la década del 20, y continuaron siéndolo hasta 1968, año en que entra en rigor la denominada Ley Raggio sancionada por Onganía; que ponía fin al congelamiento de los arrendamientos rurales que regían desde 1942 y que 
además, permitía el desalojo de los arrendatarios y aparceros por parte de los propietarios de las estancias.

En el caso de Centella, así como en otras estancias, se puede inferir que los propietarios impulsaron la conformación de este tipo de explotación de "colonos de arrendatarios", fundamentalmente por tres motivos. El primero de ellos se relaciona con que la colonización en sí misma, implicaba para los estancieros desprenderse de sus tierras; ya que en las experiencias colonizadoras los agricultores se convierten en propietarios. De más está decir que esta situación no hubiese sido aceptada así como tampoco impulsada por los mismos; siendo necesario para ello llevar adelante políticas de expropiación; lo cual nos lleva a nuestro segundo motivo, relacionado con una cierta pasividad del Estado provincial. Para que las empresas colonizadoras fueran exitosas, se necesitaba de un rol activo del Estado. No sólo en cuanto al impulso y el sostenimiento de las mismas por ejemplo en lo que a infraestructura se refiere; sino a partir del fomento de las colonias en tierras fiscales o con las mencionadas políticas de expropiación. Con el establecimiento de las explotaciones de "colonias de arrendatarios", el Estado provincial actúa de manera limitada. Impulsa efectivamente el establecimiento de las seis colonias oficiales mencionadas, pero sin entrar en conflicto con los terratenientes, derivada de políticas masivas de expropiación de tierras. Un tercer y último motivo tiene que ver, con las características concretas de los agricultores en la provincia a partir de su escaso o nulo capital, que impedían que se transformen en potenciales arrendatarios. Si bien existía en la provincia el marco legal y regulador que impulsaba y fomentaba la colonización y los arrendamientos a partir de la Constitución y la ley provincial de Transformación Agraria; la situación real de contar con arrendatarios prósperos en la provincia era escasa; debido fundamentalmente al ya señalado estancamiento general de Entre Ríos, producido por el aislamiento generado a partir de la expansión del ferrocarril en otras regiones en las décadas anteriores a 1930, y por el impacto de la Crisis del 29 y su posterior recesión. Estos tres motivos (la negativa de los terratenientes a desprenderse de sus tierras, la necesidad de un Estado activo y la situación real de los agricultores) llevaron a que la salida ideada por los estancieros para el usufructo de la tierra; con el visto bueno del Estado provincial, haya sido la de conformar estas "colonias de arrendatarios". Esta situación, sin dudas no favorecía a los agricultores a largo plazo, ya que el acceso a la propiedad de la tierra dentro de la estancia estaba bloqueado, pero dada su situación económica; contaban con la posibilidad de pago con parte de la cosecha, y no con dinero o adelantos en efectivo característicos de los contratos de arrendamientos. Es decir que hablamos de formas más cercanas a la mediería y de una economía de subsistencia. A la inversa era la situación de los propietarios: no contarían con dinero o adelantos en efectivo pero resguardaban la propiedad de la tierra; más allá de la imposibilidad de expulsar a los colonos desde 1942; y disponían de parte de la cosecha para ser colocada por ellos mismos en el mercado. El Estado, al impulsar los seis proyectos mencionados, evitaba la posible presión social derivada del impacto en la provincia de 
la Crisis de 1929 y su posterior recesión; y a su vez, al apoyar este tipo de emprendimientos eludía el conflicto con los terratenientes, evitando así la expropiación de tierras para la conformación de otras colonias más allá de los seis proyectos concretados y mencionados. Hablamos entonces de un delicado triple equilibrio entre los agricultores, el Estado provincial y los terratenientes.

Marcoz Henchoz ofrece una mirada general al plantear que en la zona en la que se encuentra Centella, "las distintas estancias que forman esa región, cuyos propietarios estaban familiar y comercialmente relacionados, decidieron formar colonias; por temor a la politica que venia desarrollando el CAN en materia de expropiaciones, llamando a agricultores de la región para tal fin".(31) Teniendo en cuenta además que a nivel nacional " $L a$ Ley de Colonización $N^{\circ} 12.636$ promovia la formación de colonias privadas (Articulo 57) que aceptando las normas del Consejo Agrario se organizaban subdividiendo los campos",(32) entendemos el marco legal en el que se ampararon los propietarios de Centella para continuar con este tipo de explotaciones. Al ser sancionada en 1940, nos posiciona una vez más en que las leyes nacen para refrendar situaciones preexistentes, tal es el caso de la conformación de la "colonias de arrendatarios" a las que hacemos referencia. Colonias que son anteriores a la sanción de la ley.

Específicamente dentro de la estancia Centella, según se recogió de las entrevistas, existían dos de estas "colonias de arrendatarios": la de "rusos" y "criollos". La denominación "rusos" se realiza de manera general y no por procedencia o descendencia étnica de los habitantes, más allá de la importancia de los alemanes del Volga en la región. En las entrevistas se hablaba de la colonia de "rusos" en el lado norte de la estancia, mientras que los "criollos" se asentaban en el lado sur, sin contacto entre ellos pero con las mismas condiciones en cuanto al porcentaje de la cosecha entregado a la estancia. Estos "colonos-arrendatarios", llevaban adelante la explotación de la tierra, en la cual la agricultura era la actividad más importante, aunque no la única en la familia que nos ocupa. Alrededor de veinticinco familias estaban dedicadas al trabajo rural en la "colonia criolla”. Cada colono tenía para la explotación entre 50 y 75 hectáreas, por lo que la distancia lineal con los vecinos no era menor a quinientos metros. Los campos estaban separados por alambrados y entre los lotes, existían calles bien delimitadas. Cada familia de esas veinticinco que componían la "colonia", tenía el campo asignado para producir y la vivienda dentro del lote o chacra. A excepción de la familia Bergara/Marín que contaba con animales y de dos hermanos de Lucila que trabajaban de techistas; el resto de los "colonos-arrendatarios" sólo se dedicaba a la agricultura, y eventualmente se empleaban como mano de obra en los trabajos de alambrada de campos que tomaba Jacinto, generalmente en estancias cercanas.

Las tareas solían comenzar alrededor de las cinco de la mañana y se desarrollarán en diversos apartados, tales como el trabajo de alambrada, el trabajo agrícola y la casa y la vida cotidiana. En el trabajo original se analizan además, las fiestas de navidad y año nuevo, diversos festejos y la 
educación, religión y política. Por motivos de extensión estas temáticas serán excluidas del presente artículo.

\section{4- Sobre "colonos-arrendatarios": la familia Bergara/Marín en la estancia Centella}

Creemos conveniente como inicio del presente apartado retomar o al menos, aproximarnos al concepto de familia. Para ello, siguiendo a Susana Torrado, diremos que una unidad familiar "es un grupo de personas que interactuan en forma cotidiana y permanente, a fin de asegurar mancomunadamente su reproducción biológica, la preservación de su vida y el cumplimiento de todas aquellas prácticas que coadyuden a la optimización de su posición social'.(33) Por su parte, José Luis Moreno, plantea que se debe considerar a la familia como "un continuo o un largo recorrido que parte desde el rito del matrimonio, que incluye los hijos y sus cónyuges, parientes cercanos y lejanos, cosanguineos y politicos, y una serie de individuos de las más diversas identidades -parientes o no, como los agregados domésticos y esclavos-que conviven, mantienen fuertes $y$ solidarios vinculos interpersonales".(34) En principio, encontramos una diferencia en términos generales ya que para Moreno el concepto de familia es más amplio, sobre todo al incluir en ella a los parientes lejanos fuera del núcleo primario, tal como haremos en este trabajo; y para Torrado, "la naturaleza de la información disponible excluye la posibilidad de indagar acerca de la naturaleza de los grupos de parentesco que excedan el criterio de corresidencia".(35) Ambos coinciden, en darle al matrimonio un rol fundamental ya que, como dijimos líneas arriba, para Moreno la familia parte desde el rito del matrimonio y para Torrado "la familia comienza en el momento en que un hombre y una mujer deciden formar una unión o pareja",(36) más allá de que esas uniones "puedan formarse por distintas vias, mencionando el matrimonio como unión legal y las uniones consensuales, en las que no media ninguna formalidad o ceremonia".(37)

En nuestro caso, la historia familiar se inicia con el matrimonio contraído entre Jacinto Bergara y Lucila Marín el 29 de agosto de 1925 en la ciudad de Concepción del Uruguay; y se desarrolla con el nacimiento de sus hijos e hijas entre 1925 y 1946: Bernardo (1925), Arturo (1927), Zulema (1928), Augusto (1929), Antonio (1931), Ramón (1933), Miguel (1935), Saturnina Teresa (1936), Juan (1939), Francisco (1942), Ester (1944) y Hugo (1946).

Debemos mencionar por cierto, dos características en cuanto a su estadía en la estancia. En primer lugar, se trata de familias estacionales a mediano plazo en cuanto a la estabilidad. Recordemos que Scobie plantea que "el arrendatario era implacablemente desplazado de parcela en parcela porque el estanciero necesitaba la tierra para criar vacunos u ovinos",(38) es decir que al cabo de unos años abandonaban su lugar de residencia para trasladarse a otro lugar en relación a las decisiones productivas de los propietarios de la tierra. Las familias que se encontraban en Centella, en determinados casos por disposición de la estancia, debían trasladarse a otro lugar. Se mencionaron en diversas entrevistas tres traslados: de 
la denominada "Colonia San José" a la "Colonia Centella", y de esta última a la "Colonia El Salto" o "Salto de Piedra". En segundo lugar, una característica importante es la relativa estabilidad de los hijos en el hogar, y por lo tanto (en relación al medio rural en el que habitan), el permanente protagonismo en las actividades productivas, de trabajo y, por ende, en la vida cotidiana. Esta situación se ve alterada debido a la existencia de tres factores desarrollados posteriormente en el apartado "La Urbanización familiar": el acceso de los hijos a la educación; las pautas matrimoniales y por último, la búsqueda de nuevas oportunidades y horizontes laborales. Cada uno de estos factores actuó en diferentes momentos en los hijos e hijas, condicionando la permanencia de los mismos en la Estancia. Fuera de esos parámetros, la familia comparte el hogar, y por lo tanto las actividades productivas por un período extenso si lo medimos en función de tiempos familiares.

En relación a la economía doméstica, recordemos que para Michael Anderson se trata sobre todo de "las estrategias empleadas por los miembros de la familia para mantener el nivel de vida acostumbrado tanto para ellos en el presente como, en ciertas circunstancias, para ellos y sus descendientes en el futuro".(39) En este sentido, existen diversos tipos de actividades en el seno familiar reconstruidas en base a las entrevistas mencionadas: el trabajo de alambrada, la agricultura y las actividades de la casa propiamente dichas. El trabajo de alambrada proveía de recursos monetarios directos, mientras que las otras actividades pueden subdividirse en relación a su utilización y/o aprovechamiento familiar. Los productos obtenidos de la agricultura, tenían diversos destinos, de los cuales se pudieron reconstruir cuatro de ellos: una parte expresada en porcentaje (medida en cantidad de bolsas), eran entregados a la estancia, otra parte era trocado por bienes de consumo familiares y elementos de trabajo, otra parte era vendida y una parte menor era utilizada como alimento del ganado. Con respecto a las actividades económicas de la casa propiamente dicha, se distinguieron aquellas actividades destinadas al consumo propio, como el caso de los productos de la quinta; y por otro lado, un tipo de producción mercantilizada generadora de excedente proveniente de la venta de ganado, pollos y huevos. Por ser generadora de recursos monetarios directos, nuestra descripción de la cotidianeidad comienza con el trabajo de alambrada.

\section{1- El trabajo de alambrada}

Con respecto a este trabajo, Jacinto lo realizaba con jornaleros, sus hijos mayores y familiares de confianza. Permanecían en el lugar donde se realizaba el trabajo en lo que denominaban "campamentos", en el que instalaban las "carpas". Estas "carpas" eran construcciones de chapa que se preparaban para que la gente que trabajaba con Jacinto se instale y pernocte mientras duraba el trabajo, independientemente si eran días, semanas e incluso en alguna oportunidad, meses. Estas carpas se armaban con chapas denominadas de represa (de tres por dos metros aproximadamente); colocando cinco chapas a cada lado y una cumbrera 
en el medio. Allí descansaban al mediodía, pernoctaban y se guardaba la mercadería necesaria, los utensilios de cocina y las herramientas. Las comidas, así como los desayunos estaban a cargo de un cocinero contratado a tal fin, que además era el encargado de mantener el fogón prendido. Generalmente desayunaban leche que traían de la casa de algún vecino cercano al "campamento" o restos de la cena. Los almuerzos y cenas variaban entre pucheros, guisos, asados, o comidas preparadas en una olla con carne de vaca o cerdo, dependiendo de la mercadería y del cocinero. Por las noches luego de la cena y alrededor del fogón o de un "sol de noche" con la compañía del mate o las cartas; conversaban sobre el trabajo, contaban anécdotas o hablaban de fútbol y de carreras de caballos, denominadas "cuadreras". Esas "carpas" además, oficiaban de refugio en el caso de lluvias o tormentas, ya que en momentos de precipitaciones o fuertes vientos no se trabajaba.

El trabajo de alambrada propiamente dicho, consistía en cavar pozos de aproximadamente setenta centímetros de profundidad, para luego colocar los postes de madera de ñandubay; con las correspondientes varillas intermedias. La alambrada generalmente era de "siete hilos", de los cuales el de púa era el segundo comenzando de arriba hacia abajo. La cantidad de "hilos" era fundamentalmente para evitar el paso de animales más pequeños a los campos lindantes. Los listados de materiales eran confeccionados por alguno de los hijos de Jacinto, y en él se detallaba la cantidad de madera necesaria, los rollos de alambre y el precio del metro lineal de alambrado. Estos eran presentados según el caso a los capataces, encargados o dueños de la estancia en que se realizaba el trabajo; y eran ellos los encargados de proveer todo el material necesario. Dependiendo del tamaño de la zona a alambrar, variaba la cantidad de materiales, pero nunca eran menos de cuatrocientos postes y por lo menos, entre treinta o cuarenta rollos de alambre.

Se trabajaba desde la salida del sol, luego de desayunar en el campamento, hasta el mediodía. A esa hora se dirigían nuevamente hacia la carpa en donde descansaban y almorzaban. Alrededor de las catorce horas comenzaban nuevamente las tareas, hasta la puesta del sol. Los hijos recuerdan que no había trabajo liviano, sino que todo lo que se hacía era trabajo pesado: cavar los pozos, apisonar la madera y agujerear los postes y las varillas con un taladro manual. Los trabajos generalmente se realizaban dentro de la estancia Centella, así como en estancias vecinas. Se delimitaban lotes y campos que, en general, serían ocupados por "Colonos-arrendatarios" o colonos propiamente dichos como en el caso de la "Colonia Oficial El Potrero", trabajo realizado a fines de la década del 40 y principios de los 50; luego de la expropiación de las tierras pertenecientes en parte a la familia Unzué. El precio era por alambrada lineal y en ese momento se cobró cincuenta y dos centavos el metro. Para ese trabajo, Jacinto contó con cuatro campamentos de alrededor de ocho personas cada uno. Dependiendo de la zona a alambrar, se colocaban los postes y las varillas necesarias. En zonas de la "Colonia Oficial El Potrero", los postes se colocaban a doce metros de distancia con cinco varillas intermedias y tres hiladas de alambre; ya que no era un alambrado 
para hacienda, sino para delimitar calles y los terrenos de los futuros pobladores, que en este caso sí se ajustan a la idea tradicional de colonos. Las calles solían tener cuarenta metros de ancho y los terrenos variaban su superficie, pero generalmente eran mayores a 50 hectáreas, es decir que la línea de alambrada tenía mínimamente un largo de mil metros por quinientos de ancho. En ese tipo de trabajos, la tarea se simplificaba, ya que los postes requerían sólo de tres agujeros, y se colocaban a doce metros con cinco varillas entre uno y otro poste. En otras zonas de la misma alambrada, donde se debía evitar el paso del ganado, era necesaria la colocación de siete hilos de alambre y los postes se colocaban a menor distancia, lo cual implicaba no sólo cavar más pozos y agujerear más postes y varillas, sino mayor cantidad de orificios en los mismos. Los alambres más cercanos a la superficie se situaban a menor distancia para evitar el paso de las ovejas y, como dijimos anteriormente, el de púa era el segundo si contamos de arriba hacia abajo. En ese momento, en la "Colonia Oficial El Potrero" se alambraron cinco calles; numeradas del uno al cinco. La más larga se extendía desde la antigua Ruta No 14 (actual Ruta Provincial No 42), hasta las cercanías del Río Uruguay; encontrando en su trayecto dificultades en el terreno como zanjas y bañados, por lo que el trabajo se complicaba, ya que la línea de la alambrada debía respetarse. El encargado de tomar la línea inicial era Jacinto. En un extremo se colocaba una bandera blanca de unos dos metros de alto, y otra bandera a una distancia de mil metros. El punto intermedio se tomaba como referencia y una vez que estaba alineada, se plantaba un jalón para tomar las referencias. La tarea se realizaba "a ojo", sin medios tecnológicos. Una vez que estaba tomada la referencia se comenzaban a cavar los pozos y se colocaban los postes, de madera de ñandubay. La particularidad de estos postes es que no son rectos, por lo cual siempre se pronunciaba la frase "cada palo tiene su vuelta", con el objetivo que los postes que van conformando la línea, no desvíen ni tuerzan la alambrada. En el oficio le llamaban "parar la madera". Los postes se agujereaban luego de ser colocados, no así las varillas. Estas se agujeraban en el campamento por una persona asignada especialmente a la tarea.

En tiempos de cosecha, se intentaba dar prioridad a la misma, es decir que se procuraba no ocuparse de los contratos de alambrada, salvo excepciones como la mencionada del trabajo en la "Colonia Oficial El Potrero". Hacia el año 1965 finalizaron los contratos de alambrada y coincidente con ese año, la mayoría de los hijos ya no estaba en la Estancia. Sólo permanecían los dos hijos menores.

\section{2- El trabajo agricola}

A raíz de su trabajo de alambrada, en muchas oportunidades Jacinto y los hijos mayores que permanecían en la estancia, se ausentaban de la casa durante días e incluso semanas y, por ende, de las actividades productivas propias de la casa. En esos casos, el trabajo agrícola era realizado por peones contratados a tal fin, que compartían la cotidianeidad del hogar. En el caso de que los hijos mayores se encontraran en la casa, eran ellos los 
encargados del trabajo. A medida que los hijos menores iban creciendo, tenían participación directa en estas tareas.

La siembra, mantención y cosecha de los cultivos, junto con la cría de animales y las actividades en la quinta (analizado líneas abajo en "La casa y la vida cotidiana") eran los trabajos más importantes en las actividades económicas que rodeaban el hogar. Con respecto a la siembra, en un primer momento el arado de la tierra se realizaba con caballos y arados de una sola reja. Antes de realizar esta tarea, el campo debía abonarse con bosta de vaca para mejorar el rendimiento del suelo. La bosta era embolsada principalmente del campo en el cual se encontraban los animales y trasladada hacia la zona de cultivo en carros. A principios de los años 50, coincidente con el proceso de mecanización del agro impulsado desde el Estado, Jacinto compró un tractor usado y un arado de levante automático, con lo que las tareas de campo se aliviaron considerablemente. Detrás del tractor colocaban la rastra de ocho cuerpos que cubría la semilla. A mediados de la misma década, también poseía una máquina cosechadora que había comprado usada y fue acondicionada a nueva. Es de destacar en este sentido, que la familia no se encontraba ajena al mencionado proceso de mecanización. Si bien tanto el tractor como la cosechadora eran usados, se logra la inserción en dicho proceso.

En los tiempos de la cosecha, se sumaban otras personas; algunos de ellos primos hermanos de Lucila que, junto a la familia en pleno estaban al servicio de la misma. Esta cosecha se acopiaba en un Galpón cercano a la casa, donde el cereal era embolsado y apilado. Una vez realizada esta tarea, el porcentaje correspondiente a la estancia era llevado a un galpón principal, donde previamente se realizaba el control en lo que se denominaba "el escritorio". Un inspector de Centella, controlaba en cada chacra la cantidad correspondiente a la estancia, y una vez anotadas en planillas la cantidad de bolsas, estas se cargaban en un carro grande con capacidad para 50 bolsas, para ser trasladadas al galpón principal. El acuerdo con los dueños por el porcentaje de la cosecha correspondía a tres productos: trigo, avena y sorgo; quedando exceptuado el lino. En el "escritorio" se informaba la cantidad de bolsas que se transportaban y se descargaban luego con personal contratado por Centella. Desde allí se cargaba en camiones cuyo destino era desconocido por los colonos.

El porcentaje, según se recogió de las entrevistas, fue variando con el paso del tiempo e inferimos que los diversos datos recogidos, se debe a la disparidad de edades de los entrevistados y sobre todo al momento en que iban asumiendo el protagonismo en las actividades productivas. Hacia mediados de la década del 30, era del 6\%. Con el correr de los años este porcentaje se fue incrementando hasta llegar en los años 50 al 12\%; y al $15 \%$ en la década del 60 . No se identifica en la familia que nos ocupa situaciones de conflicto o crisis como los "pequeños conflictos" y "grandes crisis" desarrolladas por Juan Manuel Palacio;(40) sino simplemente un mayor control por parte de la estancia en lo que se refiere a la cantidad de bolsas correspondientes a cada colono, control llevado adelante por el inspector, que entra en escena en la década del 50. 
Como se dijo anteriormente, previo al traslado de la cosecha al galpón principal de la estancia, ésta se acopiaba en otro galpón que se encontraba en la chacra de la familia. El resto de la cosecha, una vez que se entregaba el porcentaje a la estancia, tenía tres destinos: Colonia Elía, Gualeguaychú y Concepción del Uruguay, transportada en carros. El trigo y el lino se trocaban en almacenes de "Ramos generales" por bolsas de harina, arroz, fideos, azúcar y yerba entre otros productos. El maíz era mucho menor en relación a los otros dos ya que se lo utilizaba como alimento de los animales. A Colonia Elía se acarreaba poca cantidad, aproximadamente cuatro o cinco bolsas de trigo o lino. La mayor parte de la cosecha se trasladaba a Gualeguaychú y Concepción del Uruguay en otro carro con capacidad para cincuenta bolsas de trigo. En la primera de las ciudades el cereal se vendía a la firma Bunge y Born, que se encontraba en los galpones de la Estación de trenes de Gualeguaychú. Con respecto a la segunda, las bolsas se trasladaban a la firma "Degregori Compañía", que por ese entonces tenía un importante almacén de Ramos Generales en las afueras de Concepción del Uruguay. En un primer momento se viajaba, y ya hacia fines de los años 50 y en la década del 60, transportes de la firma ingresaban a la Estancia. El acuerdo con Degregori consistía en un primer momento en lo que comúnmente se denomina "fiado". Es decir que en el almacén se adquiría lo necesario y, una vez levantada la cosecha, se pagaba con una determinada cantidad de bolsas. Recordemos que Palacio destaca que en Coronel Dorrego "funcionaba un circuito local de crédito informal en el cual los propietarios dueños de estos almacenes de ramos generales ofrecian crédito a los agricultores establecidos en su área de influencia".(41) En nuestro caso este circuito de crédito local se asemeja en cuanto al "fiado" pagado con la cosecha, pero se diferencia ya que el almacén de Degregori no era propiedad ni se relacionaba directamente con Centella. Era la familia la que tomaba la decisión de comerciar con ellos. Ya en la década del 60 los camiones de la firma ingresaban hasta la chacra, cargaban las bolsas y luego Jacinto y alguno de sus hijos se trasladaban al almacén con el carro dos o tres veces al año y adquirían botas, equipos de arreos, recados, maneas, repuestos de máquinas, arados, bolsas de harina, jabones, azúcar, fideos y yerba entre otros productos. Es decir que en Concepción del Uruguay la cosecha se trocaba por mercadería.

Además del cultivo y el trabajo de alambrada; como se señaló en páginas anteriores, Jacinto arrendaba otro campo dentro de Centella, de cincuenta hectáreas, en el que se criaba ganado, fundamentalmente bovino y caballar. Las vacas eran utilizadas para el ordeñe y en el caso de los caballos para transporte, ya sea en los carros o con montura; y para tiro del arado, al menos hasta el ingreso al proceso de mecanización mencionado líneas arriba. Asimismo, en el invierno se "facturaban"(42) cientos de chorizos. Para ello se mataba una ternera conjuntamente con un porcino y se preparaban embutidos durante dos o tres días. Además, los hermanos mayores realizaban castraciones, sobre todo en las yerras. Cabe recordar que, dentro de la Estancia, el resto de los vecinos no poseían animales y; a excepción de dos hermanos de Lucila que se dedicaban a realizar techos de paja y construcciones de distinto tipo, tampoco tenían 
ingresos monetarios como Jacinto por su trabajo de alambrador. Sólo se dedicaban a la agricultura.

\section{3- La casa y vida cotidiana}

Mencionábamos anteriormente que dentro de la Estancia no siempre estuvieron asentados en el mismo sitio. En un primer momento se establecieron en la denominada "Colonia San José". Hacia finales de la década del 30 fueron trasladados a la Colonia denominada "Centella" y hacia 1942 a la "Colonia El Salto", donde permanecieron hasta 1968. La mayor cantidad de testimonios de las entrevistas y de la reconstrucción de la vida cotidiana, corresponden a este último período, es decir al de la "Colonia El Salto". La casa tenía paredes de barro y techo de paja, de importantes dimensiones (diez metros de largo por cinco de ancho aproximadamente) y contaba con tres habitaciones, destinadas al matrimonio, a las hijas mujeres y a los hijos varones; además de la "cocina-comedor" y una habitación denominada almacén o despensa. Lucila se encargaba de la supervisión de las actividades productivas que proveían la casa. Lo primero que hacían al levantarse era desayunar, generalmente mate o café para luego pasar al ordeñe de las vacas. Las mismas se encontraban en otro lugar de la Estancia (en el mencionado campo arrendado por Jacinto para la cría de ganado); y eran arriadas por los hijos menores hasta el lugar de ordeñe. Una vez finalizada la tarea, las trasladaban nuevamente para que pastaran. Esta tarea se realizaba cotidianamente, independientemente del calor o el frío. La leche obtenida se hervía para preparar café con leche para toda la familia, para los peones que realizaban el trabajo del campo y para elaborar quesos caseros y manteca. Los hijos menores del matrimonio colaboraban con los baldes de leche y el resto que no se utilizaba para la elaboración de algún producto, era vendida a las distintas familias de la Colonia.

Luego del ordeñe y el desayuno, se barría el patio y se daba de comer a los animales (gallinas, porcinos y pavos), además de lavar la ropa a mano y limpiar la cocina. En el predio que correspondía a la casa existía una quinta, situada a unos quinientos metros de la vivienda (para evitar que las gallinas comieran las verduras), y más cercano a la vivienda un gallinero; del cual se extraían aproximadamente cien huevos diarios. Estos huevos (así como también los pollos); directamente los recolectaba una persona a la que llamaban "bolichero". El dinero obtenido por la venta de los animales o huevos, era dinero del que disponía Lucila. El ganado porcino era criado y utilizado como alimento de forma directa en asados o estofados; y también, como se mencionó, para elaborar chorizos. Estos eran consumidos durante el desayuno antes de salir a arar o por la noche, luego de la cena acompañados de una taza de café con leche.

El agua era obtenida por medio de una bomba, cuyo principal objetivo era la provisión para las diversas actividades domésticas tales como cocinar, lavar la verdura o la ropa en forma manual; así como también para el aprovisionamiento de los bebederos para los animales. Lucila daba la orden de llenar los mismos y cualquiera de los hijos o hijas 
que se encontraba en la casa tenía la tarea de accionar manualmente la bomba durante dos o tres horas. Con respecto al almuerzo, se comenzaba a realizar una vez finalizadas las tareas domésticas antes descriptas, alrededor de las diez y media de la mañana. Se almorzaba principalmente fideos caseros, amasados en principio por Lucila, y luego por sus hijas. Los fideos eran acompañados por salsa o estofado. El pavo también era un plato que solía estar presente, cocido al horno en la denominada cocina económica que funcionaba en base a leña, que a su vez oficiaba de calefacción para la casa en invierno. Las verduras de la quinta eran utilizadas para engrosar los pucheros que se preparaban. Abundaban tomates, papas, cebollas, zapallos, lechuga, perejil, batatas, calabazas y chauchas; además de sandías y melones.

El piso de la casa era de tierra, y al mismo se le realizaban diversos dibujos decorativos de variadas formas. La técnica consistía en mezclar en un balde tierra roja con arcilla y, con la ayuda de una bolsa de arpillera se realizaba el trabajo. Tardaba aproximadamente medio día en secar y daba la sensación de ser un piso de material. A esta tarea decorativa se le sumaba el mantenimiento del jardín, donde abundaban las flores y plantas de varias especies, con preponderancia de jazmines, achira, pensamiento y angélica. Una característica destacada era la frescura de la casa, producto de la sombra de los paraísos que la circundaban. Más allá de esta situación, no fueron pocas las noches de verano en que, debido a las altas temperaturas o la pesadez del tiempo; los hijos solían dormir fuera de la vivienda. Los catres eran sacados de las habitaciones y la casa, y pernoctaban debajo de los árboles, hasta alrededor de las tres o cuatro de la mañana; hora en la que ingresaban nuevamente.

Hacia principios de la década del 50 , adquirieron un molino de viento (denominado molinillo), que se utilizaba para cargar las baterías de luz y de la radio. Se prestaba particular atención a las novelas, y al valor del cereal y el huevo. Asimismo, la presencia de la música estuvo marcada desde diversos géneros, como el tango, el folclore, chamamé, música clásica e incluso el rock. Esta forma de vida se distingue notoriamente de la caracterización del agricultor y su familia desarrollada por James Scobie(43) y Juan Manuel Palacio(44), salvo en los materiales utilizados para la construcción de la vivienda que coinciden a su vez con Gallo(45): barro y paja. La diferencia temporal de nuestro trabajo con los estudios anteriormente citados, sumado a las estrategias de producción que incluían ganado y el ingreso monetario derivado del trabajo de alambrador, seguramente llevaron a que las condiciones materiales y de vestimenta así como las costumbres de higiene y alimentación, difieran sustancialmente en la familia que nos ocupa de aquellas que analizan principalmente Scobie y Palacio, más allá que el nuestro es un estudio de caso sobre una familia y no un universo más amplio.

Además de las actividades netamente productivas y decorativas, Lucila se encargaba de confeccionar parte de la ropa de la familia con una máquina de coser obtenida a través de la Fundación Eva Perón; máquina que la acompañó hasta los últimos días de su vida. La ropa se planchaba con una plancha de brazas; tarea realizada por Lucila y las hermanas 
mujeres. Tanto Jacinto y Lucila como sus hijos e hijas le prestaban especial atención a la vestimenta y al arreglo personal. Los hermanos varones solían lucir bombachas de campo con tablas y camisas almidonadas, utilizadas principalmente para las “salidas".

Llegada la noche solían cenar todos juntos; más allá que en muchas oportunidades tanto Jacinto como sus hijos mayores no estaban presentes, ya que el trabajo de alambrada o el mal estado de los caminos los obligaba a permanecer en los "Campamentos". Cenaban generalmente guisos, o bifes de chorizo condimentado, acompañados de ensaladas. Al finalizar la cena, era infaltable la sobremesa y cuando estaban en la casa, Jacinto y sus hijos acostumbraban a tomar una taza de café con leche con chorizo y pan casero.

No se observa la situación del aislamiento rural que plantea Taylor (46) en cuanto al círculo familiar, sino una situación más cercana a la descripta por Balsa (47) en relación al fortalecimiento de los lazos familiares. Muchas tardes, Lucila solía visitar a los vecinos (en algunos casos familiares directos), acompañada de sus hijas o nueras. Para estas visitas era necesaria una extensa caminata, ya que recordemos que cada casa de familia estaba separada por una distancia no menor a quinientos metros. Las visitas se realizaban independientemente del calor o frío, luego del almuerzo.

\section{5- La urbanización familiar entre las décadas del 50 y del 60}

Anteriormente mencionamos la existencia de tres factores que determinaron el alejamiento en diversos momentos de los hijos e hijas del seno familiar y; por lo tanto, de las actividades productivas, del medio rural y de la cotidianeidad del hogar. Estos factores son: la educación, las pautas matrimoniales y, la búsqueda de nuevos horizontes y oportunidades laborales.

Con respecto al primero de ellos, la educación afectó directamente a Bernardo y Juan; primer y noveno hijo respectivamente. No observamos la situación que describe Balsa, (48) ya que en nuestro caso que no se trató en relación a la educación, del traslado familiar completo; sino de dos de los hijos que abandonaron la colonia a corta edad con el objetivo de realizar sus estudios secundarios. Ambos, abandonaron la Estancia a los doce años de edad para instalarse en casas de familiares en las cercanas ciudades de Gualeguaychú y Colonia Elía respectivamente; más allá de que Juan finalmente se instaló en Gualeguaychú. Ambos cursaron el secundario en el Colegio Nacional y si bien fueron los únicos de los hijos que culminaron estudios de nivel medio en ese tiempo, cabe destacar que accedieron a la educación secundaria en tiempos en que se reservaba para escasos segmentos de la población. Si bien no se trata en estos casos de traslado familiar completo como lo plantea Balsa sino de casos específicos de dos de los hijos que abandonaron la colonia a corta edad con el objetivo de realizar sus estudios secundarios, son tomados como parte de la urbanización ya que; salvo para el período de vacaciones escolares, no retornaban a la estancia y por lo tanto durante gran parte del año se 
encontraban ausentes de las actividades productivas y la cotidianeidad. Además, tal como la casi totalidad de los hijos/as, no continuaron ligados a actividades agropecuarias una vez abandonado el hogar.

Con respecto a las pautas matrimoniales, las mismas afectaron directamente a las hijas mayores (Zulema y Teresa), y parcialmente a Augusto. Con respecto a este factor, podemos encontrar elementos de homogamia, "entendiendo a esta como la tendencia de hombres y mujeres a unirse a un compañero que pertenezca a su mismo entorno social";(49) así como de endogamia, "es decir el hecho de casarse con alguien del mismo ámbito geográfico". (50) En los hijos mencionados, la situación de homogamia y endogamia es claramente observable, ya que los tres se unieron con personas de condición social similar y del mismo ámbito geográfico. De hecho se instalaron en principio, más allá que finalmente recalaron en Gualeguaychú y Concepción del Uruguay; en el mismo medio social de cual provenían: el ámbito rural. Zulema permaneció durante unos meses en Centella y Teresa y su esposo vivieron durante varios años en el medio rural (sobre todo en las afueras de Colonia Elía), dependiendo del trabajo de tractorero de su esposo, hasta que finalmente se Instalaron en Concepción del Uruguay. En el caso de Augusto, cabe mencionar que al momento de contraer matrimonio en 1950; él y su nueva familia permanecieron en la Estancia por cuatro años. Su esposa participaba de las actividades de mantenimiento de la quinta y cuidado de animales junto con Lucila, su suegra. Posteriormente a Centella, Augusto se instaló junto a su familia en una Estancia en la cercana localidad de Urdinarrian; para luego recalar en el año 1957 en la Estancia San Miguel, donde era Capataz General de Majada. A mediados de la década del 60 se trasladaron a la provincia de Buenos Aires, siempre ligado al trabajo rural. Falleció en 1973 a la edad de 43 años en la ciudad bonaerense de Ramallo. A los pocos meses, Teresa y sus hijos se trasladaron a Campana, provincia de Buenos Aires; donde residían la mayoría de sus cuñados y sus suegros. Fue el único de los hijos que continuó ligado laboralmente a actividades agropecuarias una vez abandonado el hogar.

Finalmente, relacionando con la búsqueda de nuevos horizontes y oportunidades laborales, Ramón, Antonio, Miguel, Francisco y Hugo fueron los hijos que se desplazaron hacia zonas urbanas durante las décadas del 50 y 60. Las ciudades bonaerenses de Zárate (aunque esta de manera temporal), Campana y Gualeguaychú fueron las receptoras. Con respecto al por qué de este desplazamiento o la búsqueda de nuevos horizontes cabe destacar que el proceso comenzó en el año 1952, en momentos en que se notó una importante disminución en los trabajos de alambrada; ya que finalizada la alambrada de la "Colonia Oficial El Potrero", quedaban pocos territorios en la zona faltos de alambrada o que necesitaban de ellas. Esta situación motivó a los hijos mencionados, a la búsqueda de nuevas oportunidades laborales; búsqueda comenzada por Ramón. El desplazamiento hacia otras regiones no era exclusiva a nivel particular de la familia que nos ocupa. Cabe destacar que durante los años 50 y 60, hubo un marcado estancamiento en la población de Entre Ríos, situación que se profundiza en la década siguiente. Si observamos los 
datos de los Censos Nacionales, Entre Ríos pasa de 425.373 habitantes en 1914 a 787.362 en 1947;(51) es decir que, si bien no llega a duplicar a su población en el total provincial, en el lapso inter censal de 1914-1947; se acerca a esa condición; aumentando en un $85 \%$. Ahora bien, si tomamos un lapso similar al anterior (treinta y tres años), observaremos que entre los resultados del Censo de 1947 y el de 1980, la población provincial pasa de 787.362 habitantes a 908.313 , aumentando en apenas un $15 \%$ en treinta y tres años (1947-1980).

En relación a la población de los departamentos con costa sobre el Río Uruguay, observamos que durante el período 1914-1947, la casi totalidad de los departamentos de la región del Uruguay, duplican su población o se acercan a esa condición, en consonancia con los resultados provinciales. Ahora bien, tomando un período similar al arriba descripto (treinta y tres años) y comparando los datos de 1947 con 1980, el único departamento de esta región que continúa con un crecimiento sostenido de la población es Concordia; más allá de que perdiera territorios y población con la creación del Departamento de Federal en 1972 (Concordia pasa de 86.766 habitantes en 1947 a 123.190 en 1980). En el resto se observa un marcado estancamiento de la población, registrándose como mencionábamos anteriormente, descenso de la misma en varios Departamentos en el año 1980, comparándolo con 1947. Sabido es que durante el período considerado, no hubo ningún elemento maltusiano que actúe sobre la población para justificar el estancamiento o retroceso de la misma. El factor que aquí actúa no es otro que el desplazamiento de la población hacia otras regiones. En el caso específico del departamento de Uruguay, observamos que durante el período 1914-1947, la población sigue el ritmo de la provincia. Si bien no llega a duplicarse, pasa de 40.626 habitantes a 71.695; es decir que aumenta un 76\%. Sin embargo, se observa un marcado estancamiento en el período intercensal 1947-1980, aumentando sólo un 8\% (de 71.695 a 77.828 hab.); por debajo de la media provincial que arrojó un ya de por sí escaso aumento de población del $15 \%$.

En ese contexto provincial y departamental de estancamiento de la población entre 1947 y 1980, Ramón (cuarto hijo, nacido en 1933) fue el primero en abandonar la Estancia por motivos relacionados con la búsqueda de oportunidades y nuevas fuentes de trabajo en el año 1952. Una vez establecido en Campana, y dedicado al trabajo de construcción y montaje, permitió la llegada en 1956 de otro de sus hermanos desde Centella: Antonio, quien a su vez luego de unos años fue fundamental, junto con su hermano Ramón para la llegada de Juan en 1959, Miguel en 1965, Hugo en 1969 y Francisco en 1976. Estos tres últimos llegaron a través de ofrecimientos laborales de Antonio para ingresar en la siderúrgica Dálmine(52); mientras que Juan, que había abandonado la Estancia para culminar sus estudios secundarios, trabajó temporalmente en tareas de construcción para luego trasladarse al sur patagónico y Capital Federal en trabajos del área de contabilidad. Es decir que el fenómeno de urbanización de los hermanos, sigue la dirección del planteo de la ya citada obra de Balsa: crisis agrícola (en este caso estancamiento), "con expansiones industriales que demandan mano de obra 
en las ciudades"; (53) en este caso en la ciudad de Campana. Cabe aclarar igualmente que de los hermanos, tres se trasladaron directamente desde Centella hacia Campana: Ramón, Antonio y Miguel; mientras que Juan, Hugo y Francisco lo hicieron desde Gualeguaychú.

En el caso de Hugo, el menor de todos nacido en 1946 se alejó de la Estancia para realizar el Servicio Militar obligatorio y una vez concluido, se trasladó a Gualeguaychú ya que Jacinto, Lucila y su hermana Ester (única que quedaba en la Estancia con el matrimonio), habían abandonado la misma luego de rematar los animales y las maquinarias. En el caso de Ester (hija menor del matrimonio, nacida en 1944), abandonó la estancia conjuntamente con sus padres luego del remate de ganando y maquinarias para trasladarse a Gualeguaychú, en el año 1968. Ester estuvo en la Estancia hasta los últimos días y fue testigo presencial de dicho remate. Se trasladó con ellos a la ciudad de Gualeguaychú, a una casa en el casco urbano en la calle San José; vivienda en la que finalmente recaló Hugo; quien decidió trasladarse como mencionamos anteriormente hacia la ciudad de Campana un año después, en 1969. Ester se trasladó a la misma ciudad en el año 1973, donde trabajaba de modista en un taller de costura y atendía el negocio de su hermano Antonio.

A modo de síntesis diremos que el acceso a la educación afectó la permanencia de Bernardo y Juan en la Estancia, más allá de que este último luego haya llegado a Campana en búsqueda de trabajo; las pautas matrimoniales a las hijas Zulema y Teresa y parcialmente a Augusto; y la búsqueda de nuevas oportunidades y horizontes laborales en relación al contexto provincial a Ramón, Antonio, Miguel, Francisco y parcialmente a Hugo, ya que a este último no le quedó opción de abandonar la Estancia. Sus padres ya se habían trasladado de Centella a Gualeguaychú cuando retornó del Servicio Militar Obligatorio.

Las causas del abandono definitivo del matrimonio se relacionan sobre todo con dos motivos. Por un lado, los entrevistados plantearon que existió una negativa de los dueños de la estancia a seguir con el acuerdo; y por otro lado con el progresivo abandono de parte de los hijos de las actividades agropecuarias para trasladarse a las ciudades de Gualeguaychú, Concepción del Uruguay y Campana.

Con respecto al primer punto (la negativa de los dueños de la Estancia a seguir con el acuerdo), cabe recordar que, "por esos años para beneplácito de los terratenientes, se daba por concluido el régimen de prórroga automática $y$ congelamiento de los arrendamientos rurales".(54) Esta situación fue determinante al momento de que los dueños de la tierra decidan por la no continuidad del trabajo en Centella con las "colonias de arrendatarios". Esta situación era totalmente novedosa, ya que desde el año 1942, diversas Leyes y Decretos-ley, impedían el desalojo de los arrendatarios y aparceros,(55) situación que se revirtió en los últimos años de la década del 60. Es decir que uno de los aspectos tratados por Javier Balsa al respecto de "si hubo un proceso de farmerización (acceso a la propiedad) de los chacareros arrendatarios, o si los terratenientes recompusieron las viejas estancias (o constituyeron nuevas) luego de echar a los no propietarios"(56) es clara: en Centella no hubo posibilidad de acceso a la propiedad de la tierra, 
independientemente de la característica que poseían estos "colonosarrendatarios". Recordemos que Centella estaba dividida en parcelas de aproximadamente 50 a 75 hectáreas que eran explotadas por distintas familias, siendo luego de fines de los años 60 reconstituida la misma como una unidad productiva explotada ya no por colonos, sino como parte de un grupo empresario de la familia Blaquier: La Biznaga S.A. Cabe aclarar que según el testimonio de dos de sus hijos; Jacinto realizó la venta de maquinarias y animales previo al cumplimiento de la ley sancionada bajo el gobierno de Onganía, por lo que los resultados obtenidos por la venta fueron positivos. Los dueños de Centella habían advertido que posiblemente se iba a desalojar, pero como dicha advertencia se había realizado en varias oportunidades, el resto de los colonos no le dió demasiada importancia. Jacinto sí lo hizo y luego del remate, la casa donde vivían quedó deshabitada, antes que fuera cumplida la ley y se efectivizara el desalojo del resto de los colonos.

El segundo motivo (el progresivo alejamiento de Centella por parte de los hijos), se sumó al anterior; evitando así una nueva posibilidad de trabajo rural en otro lugar por parte del matrimonio y los hijos que aún los acompañaban (Ester y Hugo), trasladándose en un principio a la ciudad de Gualeguaychú. Hacia el año 1972 Jacinto y Lucila se trasladaron a Campana, a la casa en la que vivía su hijo menor, Hugo; construida con ayuda de Ramón y Antonio con el objetivo de que sus padres se trasladaran a Campana. Jacinto ya jubilado, en los últimos años de su vida, recorría las calles de Campana junto a un carrito, juntando cartones. Falleció a los 91 años, en el año 1986. Lucila, una vez en Campana, seguía ocupando el tiempo con su máquina de coser obtenida de la Fundación Eva Perón durante los años 50. Falleció cuatro años después que Jacinto, a la edad de 82 años.

\section{6- Palabras finales}

No se trató en el presente trabajo de realizar un recuento de la vida familiar año por año, así como tampoco de describir al mundo chacarero como totalidad; sino de reconstruir a partir de un estudio de caso, parte de actividades productivas y laborales, la cotidianeidad del hogar y el proceso de urbanización familiar registrado a partir de los factores analizados. Las relaciones personales, el papel de diversas instituciones como la Iglesia o la Escuela, la influencia de la política y los lazos afectivos en el mediano plazo han quedado fuera del análisis por un tema de extensión.

Ciertas obras ofrecen una visión particular de un lugar o región en momentos determinados, como en el caso de Rural life in Argentina de Taylor, Revolución en las pampas de Scobie, La pampa gringa de Gallo, La paz del trigo de Juan Manuel Palacio o El desvanecimiento del mundo chacarero de Javier Balsa. En algunos de ellos, principalmente en Taylor, Palacio y Balsa, encontramos ejemplos que aparecen en la familia que hemos estudiado; tales como el crédito, la situación de la vivienda, la vida material, las relaciones sociales y personales; así como diversas situaciones 
trabajadas en los apartados precedentes que se emparentan con las obras mencionadas.

Más allá de las lecturas relacionadas y los indicios documentales que en muchos casos oficiaron de confirmadores de datos surgidos de las entrevistas; la vida y el trabajo familiar, necesariamente descansan sobre un sin fin de anécdotas y recuerdos, sobre todo en tiempos en que esta familia fue "beneficiada", así como muchas otras, por las incesantes prórrogas que año a año iban regulando el trabajo en el campo. En el caso del trabajo rural, la familia es parte indispensable: motor y combustible.

Situados en la vida urbana, los descendientes de Jacinto y Lucila (hijos e hijas; nietos/as, bisnietos/as y tataranietos/as) poco tienen que ver en relación a lo social y laboral con la descripción realizada. En relación a este punto, podemos destacar nuevamente un fragmento de la obra de Javier Balsa estudiada con anterioridad:

"A comienzos de la década del 1990, para estudiar el impacto de la crisis de 1930 en el agro pampeano, entrevisté a viejos chacareros del sur bonaerense. A medida que avanzaban las entrevistas, otro tema fue llamando la atención: la distancia existente entre las descripciones de la vida en las chacras en las décadas de 1920 y 1930, y las caracteristicas que presentaban los propios entrevistados y sus descendientes al momento de efectuarse los encuentros. Estas diferencias no lo eran sólo en términos de dotación de recursos económicos -por cierto muy diferentes-, sino también en sus formas de vida, sustancialmente modificadas. Cuando comentaban los detalles de su infancia en la chacra, parecia que estaban hablando de otro mundo, del que ya no quedaban casi elementos objetivos y muy pocos rasgos subjetivos" (57).

Esa distancia existente entre las descripciones de la vida en las chacras y la actualidad, también lo encontramos en la familia que nos ocupa. Lo único que permanece del tiempo de Centella son los recuerdos por parte de los hijos e hijas y nietos/as mayores; de ese "otro mundo" al cual se refiere Balsa, que poco y nada tiene que ver con la vida desarrollada en las ciudades. El comercio y el trabajo industrial, fueron las actividades preponderantes en los hijos ya que como dijimos, sólo Augusto continuó ligado a actividades rurales una vez abandonado el hogar. El proceso de urbanización alejó a los/as protagonistas de esta investigación de su propia historia, y tal cual lo planteamos en la introducción las precepciones y la reconstrucción de la memoria de ese mundo es traído al presente a partir de lo que sintetizamos como añoranza. La vida en el campo es parte de otro mundo, más allá de que el estilo de vida distaba mucho de la situación de los arrendatarios que analiza Scobie. Entre los bienes materiales adquiridos por la familia podemos mencionar la radio, el wincofón, el molinillo que permitía contar con energía eléctrica, diarios, revistas, libros. Estos y otros elementos nos permiten hablar de una importante prosperidad de la familia en lo que refiere a pautas de consumo. Fernando Rochi (58) afirma que hacia fines del Siglo XIX, existió una estrategia de comercialización que cambió por completo las reglas del mercado en la Argentina: la publicidad. En este sentido, si bien nuestra historia transcurre promediando el siglo XX, el contacto con las ciudades y, fundamentalmente con los diarios y revistas que adquirían y por supuesto la radio, oficiaron de intermediarios entre los bienes de consumo y la publicidad; más allá de la capacidad económica para 
adquirir dichos productos. Asimismo, el aseo y el cuidado personal en las prendas de vestir, la alimentación variada nos ofrecen una visión de la familia ligada a un bienestar general que se extendió en el tiempo, independientemente de los gobiernos de turno. En relación a este punto debemos destacar que si bien existieron ciertos recuerdos puntuales con respecto al peronismo, tales como el acceso al crédito o la política social en relación a los útiles escolares, libros y la obtención de la máquina de coser; el golpe de 1955 y los posteriores gobiernos civiles y militares parecieron no afectar ni modificar el estilo de vida y el bienestar general de la familia.

Existieron diversas estrategias para llegar a ese bienestar general, derivadas fundamentalmente de las actividades económicas que no se agotaban en la agricultura. El excedente provenía fundamentalmente del trabajo de alambrador, la venta de ganado y de productos derivados de los animales domésticos o los mismos animales tales como los huevos o pollos; así como de la venta de una parte de la cosecha en Gualeguaychú. Otra parte de la cosecha (una vez entregado el porcentaje correspondiente a la estancia) se utilizaba para consumo propio y para la alimentación de los animales así como para intercambiar bienes que garantizaban la reproducción familiar en los almacenes de Colonia Elía y Concepción del Uruguay. A todo esto hay que sumarle el mantenimiento de la quinta de la cual obtenían una importante variedad de productos para el consumo propio. Todas estas estrategias diversificadas aseguraban la reproducción familiar.

No aparece entre las estrategias de reproducción, aquella destinada a la adquisición de tierras. Uno de los hijos entrevistados planteó que Jacinto tuvo la posibilidad de convertirse en propietario en tiempos de la alambrada de la "Colonia Oficial El Potrero", ya que el encargado de la misma le dio a elección los dos mejores lotes, ofrecimiento que fue rechazado. Una posible respuesta del por qué la negativa, tiene que ver con que la actividad considerada como fundamental en el seno familiar en cuanto a tiempo y mano de obra utilizada, era la de alambrador. Fueron los hermanos de Lucila los que le plantearon a Jacinto la posibilidad de la vida de agricultor ya que él no provenía de esa tradición, más allá que el medio en el que desarrollaba su actividad era el ámbito rural. La actividad de alambrador era más bien nómade, mientras que la agricultura necesariamente implica la sedentarización. El matrimonio y el nacimiento de los hijos seguramente llevaron a considerar otra actividad que asegure cierta estabilidad; más allá de que el rechazo a ser propietario muestre que el acceso a la propiedad de la tierra no era una estrategia pensada en términos familiares. Recordemos que al momento de la alambrada de "El Potrero", no se había iniciado el éxodo de los hijos en busca de nuevas oportunidades y horizontes laborales, razón por la cual la anterior afirmación cobra mayor relevancia. El proceso de abandono de parte de los hijos buscando nuevas oportunidades se inicia precisamente luego de concluir ese trabajo de alambrada.

Por último, diremos nuevamente que este trabajo no pretende ser más que un aporte a la reconstrucción de una parte de la vida cotidiana e identidades familiares que, en este caso se desarrolló en el ámbito 
rural en un lugar determinado. Hablamos e intentamos reconstruir la cotidianeidad del matrimonio Bergara-Marín y sus hijos e hijas en el tiempo que se establecieron como "Colonos-arrendatarios" en la Estancia Centella. Matrimonio que forjó una identidad y valores sostenidos hasta el día de hoy, según la percepción de todos/as los/as entrevistados/as, en relación a la solidaridad y compañerismo en el seno familiar.

\section{Notas}

(1) Franco Rubio, Goria. "Fragmentos de cotidianeidad. Historiar lo cotidiano", en Cuadernos de Historia Moderna No XIV, Universidad Complutense de Madrid, Madrid, 2015, p. 19

(2) Djenderedjian, Julio. Gringos en las pampas. Inmigrantes y colonos en el campo argentino, Buenos Aires, Editorial Sudamericana, 2008, p. 12

(3) Blanco, Mónica. "Colonización y política agraria en la provincia de Buenos Aires. Demandas sectoriales y respuestas oficiales durante la primera mitad del siglo XX", en Mundo Agrario, 15 (30), La Plata, UNLP-FaHCE, 2014.

(4) Ibídem.

(5) Taylor, Carl. Rural life in Argentina, Baton Rouge, Luisiana State University Press, 1948.

(6) Scobie, James. Revolución en las Pampas. Historia social del trigo argentino. 1860-1910, Buenos Aires, Ediciones Solar, 1968.

(7) Gallo, Miguel. La pampa gringa. La colonización agrícola en Santa Fe (1870-1895), Buenos Aires, Editorial Sudamericana, Segunda Edición, 1984.

(8) Balsa, Javier. El desvanecimiento del mundo chacarero. Transformaciones sociales en la agricultura bonaerense, 1937-1988, Bernal, Universidad Nacional de Quilmes, 2006.

(9) Scobie, James. Op. Cit., pp. 74/79.

(10) Gallo, Miguel. Op Cit., p. 68 y suc.

(11) Gallo, Miguel. Op. Cit., pp. 52/59.

(12) Balsa, Javier. Op. Cit., p. 58.

(13) Balsa, Javier. Op. Cit., p. 76.

(14) Anderson, Michael. Aproximaciones a la historia de la familia occidental, Madrid, Siglo XXI Editores, 1988.

(15) Moreno, José Luis. Historia de la familia en el Río de la Plata, Buenos Aires, Editorial Sudamericana, 2004, p. 13.

(16) Moreno, José Luis. Op. Cit., p. 17.

(17) Rofman, Alejandro; Romero, Luis Alberto. Sistema socioeconómico y estructura regional en la Argentina, Buenos Aires, Amorrortu Editores, Segunda Edición, 1997, p. 113 y suc.

(18) Barsky, Osvaldo; Gelman, Jorge. Historia del agro argentino. Desde la Conquista hasta fines del siglo XX, Buenos Aires, Mondadori Editores, Segunda Edición, 2005, p. 120.

(19) Ibídem. 
(20) Hora, Roy. Historia económica de la Argentina en el siglo XIX, Buenos Aires, Siglo XXI Editores, 2010, p. 75.

(21) Djenderedjian, Julio. Op. Cit., p. 302.

(22) Ferrer, Aldo; Rougier, Marcelo. La historia de Zárate-Brazo Largo. Las dos caras del Estado argentino, Buenos Aires, Fondo de Cultura Económica, 2010, p. 16.

(23) Biasizo, Rogelio. Economía de Entre Ríos en el período de intervencionismo conservador (1930-1945), Paraná, Editorial de la Universidad Nacional de Entre Ríos, 2015, p. 14.

(24) Ibídem.

(25) Ibídem.

(26) Biasizo, Rogelio. “Cambios estructurales en la economía de Entre Ríos, en el período de intervencionismo conservador (1930-1945)”, en Suplemento Ciencia, Docencia y Tecnología IV (4), Universidad Nacional de Entre Ríos, 2014, p. 40.

(27) Henchoz, Marcos. Colonia Oficial el Potrero (1946/1950) Conformación y destino de un modelo de reforma agraria durante el primer gobierno peronista en el sur entrerriano, Paraná, Editorial de Entre Ríos, 2005, p. 63.

(28) Henchoz, Marcos. Op. Cit., p. 66.

(29) Dirección General de Catastro Entre Ríos. Administradora Tributaria de Entre Ríos, División Límites Jurisdiccionales. Expediente de Geodesia y Topografía 47/28, Año 1937, Paraná, 1937.

(30) Flores Perez, Ezequiel. “¿De desocupados a Colonos? El Estado ante los desocupados en Entre Ríos, luego de 1930”, disponible en http://razonyrevolucion.org/de-desocupados-a-colonos-el-estado-antelos-desocupados-rurales-en-entre-rios-luego-de-1930/, 2017.

(31) Henchoz, Marcos. Op Cit., p. 69.

(32) Ibídem.

(33) Torrado, Susana. Historia de la familia en la Argentina moderna. 1880-2000, Buenos Aires, Ediciones de la Flor, 2012, p. 37.

(34) Moreno, José Luis. Op. Cit., p. 14.

(35) Torrado, Susana. Op. Cit., p. 38.

(36) Torrado, Susana. Op. Cit., p. 225.

(37) Ibídem.

(38) Scobie, James. Op. Cit., p. 45.

(39) Anderson, Michael. Op. Cit., p. 77.

(40) Palacio, Juan Manuel. La paz del trigo. Cultura legal y sociedad local en el desarrollo agropecuario pampeano. 1890-1945, Buenos Aires, Edhasa Ediciones, 2004, p. 160 y suc.

(41) Palacio, Juan Manuel. Op. Cit., p. 85.

(42) Denominación popular que se le da al proceso de elaboración casera de chorizos, morcillas o un embutido característico del sur entrerriano denominado butifarra.

(43) Scobie, James. Op. Cit., p. 86 y suc.

(44) Palacio, Juan Manuel. Op. Cit., p. 112. 
(45) Gallo, Miguel. Op. Cit., p. 300.

(46) Taylor, Carl. Op. Cit., p. 326.

(47) Balsa, Javier. Op. Cit., p. 82.

(48) Balsa, Javier. Op. Cit., p. 172 y suc.

(49) Torrado, Susana. Op. Cit., p. 227.

(50) Torrado, Susana. Op. Cit., p. 284.

(51) Resultados de los Censos Nacionales de Población, INDEC.

(52) Actal Tenaris-Siderca.

(53) Balsa, Javier. Op. Cit., p. 166.

(54) Rapoport, Mario. Historia económica, política y social de la Argentina, Buenos Aires, Ediciones Macchi, 2003, p. 644.

(55) Balsa, Javier. Op. Cit., p. 98 y suc.

(56) Balsa, Javier, Op. Cit., p. 92.

(57) Balsa, Javier. Op. Cit., p. 15.

(58) Rochi, Fernando. "Inventando la soberanía del consumidor: publicidad, privacidad y revolución del mercado en Argentina, 1860-1940”, en Devoto, F.; Madero, M. (Dirs), Historia de la vida privada en la Argentina, Tomo II, La Argentina Plural: 1870-1930, Buenos Aires, Editorial Taurus, 1999.

\section{Enlace alternativo}

http://perio.unlp.edu.ar/ojs/index.php/cps/index (html) 